This item was submitted to Loughborough's Research Repository by the author.

Items in Figshare are protected by copyright, with all rights reserved, unless otherwise indicated.

\title{
Design and problem-solving
}

PLEASE CITE THE PUBLISHED VERSION

PUBLISHER

(C) Loughborough University

LICENCE

CC BY-NC-ND 4.0

REPOSITORY RECORD

Liddament, Terry. 2019. "Design and Problem-solving”. figshare. https://hdl.handle.net/2134/1485. 
This item was submitted to Loughborough's Institutional Repository by the author and is made available under the following Creative Commons Licence conditions.

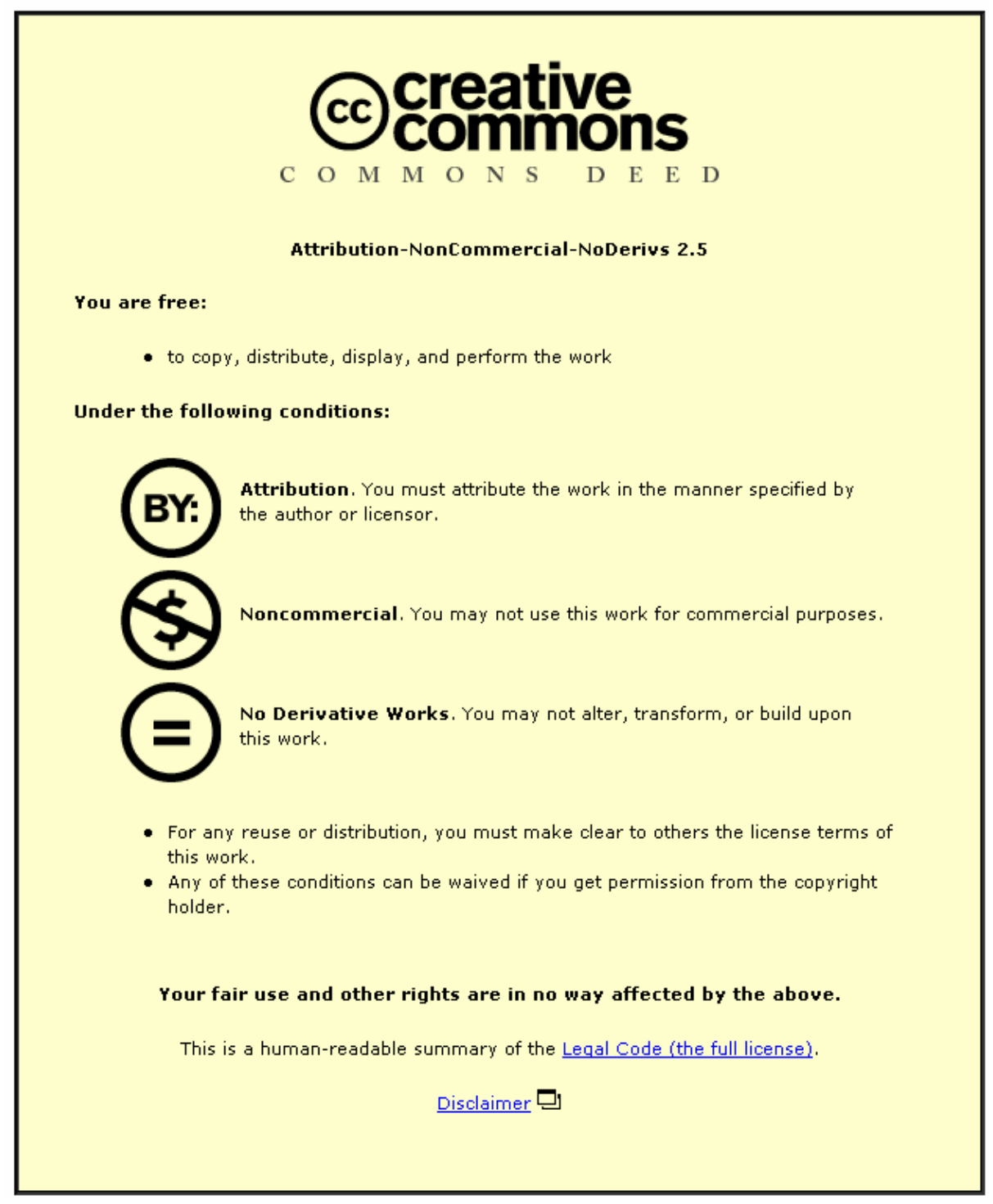

For the full text of this licence, please go to: http://creativecommons.org/licenses/by-nc-nd/2.5/ 


\title{
Design and problem-solving
}

Terry Liddament

Goldsmiths University of London

\begin{abstract}
The 'problem-solving' model of design and technological activity has emerged in recent decades, for example in recent work by APU. I have drawn attention elsewhere to some problems thrown up by the underlying epistemological assumptions typically presupposed by popular versions of the problem-solving model. Other commentators have also challenged what may be seen as a central assumption of the problem-solving activity; that it can be treated in some sense as itself a skill that may be acquired through design and technology activity, which may then be applied more generally to other problem areas, even in other domains not necessarily related to the original problem-solving context. The debate about the 'generalisability' of such (relatively) high level 'skills' as problem-solving has also invited much discussion across whole areas of learning and the curriculum in recent years.
\end{abstract}

I want in this paper to explore some of the assumptions that tend to be associated with the 'problem solving' approach to design and technology education, firstly by putting them in the context of the broader debate about 'problem solving' as a vehicle for learning. Secondly, I will argue that the problem solving model of design and technology education does little to promote our deeper understanding of the actual 'learning' involved and that we should seek to replace this model with a more comprehensive one which may more successfully capture our intuitions about the educational value of the activity.

\section{Introduction}

The 'problem-solving' model of design as an activity has become popular in recent years. It has also been applied by educationists to design as a pedagogic activity, and finds expression in a number of publications. ${ }^{1}$ The problem-solving model has a number of attractions.

Firstly, problem-solving is presented as a process. Therefore, if applied to design activity, that activity itself is (so it appears) rendered more transparent in terms of those processes. The notion of 'process' of course also invites one to consider the various elements involved. Thus 'design', in being pictured as a process, becomes a series of such elements, which follow a sequence, which in turn can be explicated. In this way, it seems that 'design' can be given a clear definition and explained, laid out, and, as an activity, made transparent.

Secondly, it follows that if design can be characterised in this way, then it becomes amenable to pedagogic treatment; the very notion of 'process' with its explicability in terms of structure and order, suggests that pedagogic programmes may be developed which aim at exhibiting this order. There is a subtle and pervasive pressure at work here; educators are usually seeking to promote effective learning and, to that extent, are likely to be attracted to the possibility of developing systematising methods in pursuit of such aims. This 'process' then becomes a vehicle for 'learning' in its own right. The 'design process' as an educational vehicle is thus born.

In what follows I will explore some of the assumptions that tend to be associated with the 'problem solving' approach to design and technology education, by putting them to begin with in the context of the broader debate about 'problem solving' as a vehicle for learning. I will then argue that this problem solving model does little to promote our deeper understanding of the actual 'learning' involved and that we should seek to augment this model with one which may more successfully capture our intuitions about the educational value of the activity.

One of the main attractions of the 'problem solving' approach, as currently conceived, is 
that it promises (or appears to promise) a general strategy which can be applied in a variety of differing contexts, and even differing domains. In a world currently subjected to an 'information explosion', with knowledge apparently proliferating at an exponential rate and with attendant pressures on the curriculum at all levels, the prospect of a 'core' of high level problem solving 'thinking skills' which can be taught in a systematic way and which might then be employed to make this vast sea of information and knowledge more manageable is of course an attractive one.

The idea is not new by any means: it owes much to Dewey ${ }^{2}$ going back to early in the 20 th century and the assumptions it incorporates about the nature of learning and the acquisition of knowledge go back even further to the early empiricists, particularly to Locke $^{3}$, for whom all learning is rooted in sensory particulars derived from immediate experience of the world. This kind of empiricist learning theory finds contemporary expression in the approach of the situated cognitivists, in locating all learning within specific contexts containing a relevant experiential component. ${ }^{4}$ However, empiricism, at least in its strong form, with its insistence that all knowledge is based on particulars of experience, has difficulty in explaining how learners ever actually acquire general concepts, ie, how learners acquire the powers of abstraction required in making the apparent move from sensory particulars to the concepts under which such particulars are subsumed. Since such concepts are an integral part of any knowledge system they have to be accounted for; even a simple observation report such as 'the red rose is in the kitchen garden' already contains general terms (ie, 'red', 'rose, 'garden' etc.). General terms are built in to the very bedrock of our language and learners master them as they acquire language skills. If there are general terms in our natural languages then 'generalisability' must, in some sense, be on the cards as a part of our conceptual framework. I am not concerned here to unravel these problems; they are still very much a part of contemporary debate about the nature of learning among philosophers, psychologists and other theorists. Rather, I wish to briefly draw attention to key aspects of the 'generalisability' issue before offering an account of design activity which I believe undercuts much of this debate.

Thus I will note that the model incorporates a generalisability thesis, which can take both a stronger and a weaker form. The stronger form makes the claim that problem solving 'skills' (along with other types of high level thinking 'skill') can be isolated and acquired (ie, taught) as skills in their own right apart from any particular context. Examples of such skills might be the ability(s) to extract relevant information, to organise material, to analyse data, to define a problem, structure the problem domain and so forth.

Such 'skills' are typically seen as part of design activity, or at least construed as a problem solving process, and various models incorporating them have become familiar in the literature on design education.

The generalisability thesis has frequently been attacked on logical grounds in that thinking in any form presupposes some specific domain or context and that therefore such thinking 'skills' (including those of a 'problem solving' variety) can only be articulated and practised within some specific domain or context. It has also been attacked on the straightforwardly empirical grounds that there is little (if any) evidence that learners are able develop such skills in a context-free situation (if indeed such a situation can be defined) . A further line of attack argues that the notion of 'skill' as it is used here is in any case mislocated. It is taken from contexts where it is quite at home, and pressed into service in contexts where it simply is not appropriate to talk of the abilities under consideration as 'skills' at all. For example, although reading is in some senses a skill, the ability to [say] read with attention to appropriate detail, to extract relevant information, to grasp new concepts and to employ these in other contexts, has so many subtle connections with personality, attitude, motivation, to say nothing of the learner's prior competence or the specific domain of employment and so on, that it is doubtful whether their acquisition could be linked with the development of skills in any 
straightforwardly intelligible way. Yet 'study skills' programmes often do claim to be able to develop these kinds of 'skill' and frequently via the most ridiculously banal exercises.

The weaker form of the thesis concedes that although the skills in question are context or domain dependent as far as their elucidation and development are concerned, once mastered, they can be transferred to other contexts and domains. We can refer to this as the transferability thesis. This appears to have greater plausibility, not least because at least some problem solving strategies do have wide application. Differential calculus (as an example from the domain of mathematics) can be applied to a wide range of engineering design problems, and with considerable success. It is of course, an algorithm, one of a large class of algorithmic problem solvers. Indeed, mathematics is a paradigm of such 'problem solving' strategies, even providing us with a putative example of 'context free' skills (ie, 'pure' maths). However, the plausibility of the transferability thesis fades somewhat when we note that such an example can be seen to fit in at one end of a wide spectrum of strategies; the very fact that it is an algorithm means that it can be applied quite mechanically, for example via a computer programme or some other calculating device. We want to say that 'problem solving skills', whatever they amount to in the context of design, consist not just in the application of such algorithms, but rather, in their intelligent (even creative) application. And this clearly takes us beyond the domain of the merely algorithmic; beyond, that is, the mechanical application of a set of 'rules', no matter how sophisticated their elucidation and formulation might be. ${ }^{5}$

What we want to say here, is that problem solving 'skills' (in common with other high level thinking skills) are not merely algorithmic in character, but probably cover a broad spectrum from the algorithmic through to the kinds of application of 'critical thinking' leading to insight, originality, and creativity in the development of solutions to 'problems'. The other end of this spectrum is often taken to be just as problematic in that 'creativity' in design (as in other areas) is thought to be essentially mysterious ${ }^{6}$ and is in sharp contrast to the kind of logical systematising characteristic of algorithmic problem solving methods.

The results of this discussion so far indicate that the high level thinking 'skills' that we are particularly interested in as far as design activity is concerned, are, in some important as yet to be elucidated sense, 'creative', requiring intelligence and insight in their application. What links the activities of 'design' and 'learning' is precisely those aspects of thinking skills that most intrigue us here: intelligent application, insight, creativity, innovation, and so forth, are the very underpinning of the conceptual growth we most associate with significant learning. As educators we worry that learners may simply apply 'problem solving processes' mechanically without any insight or real learning. We also tend to feel that to attempt to apply these methods to the insight, innovation and creativity implied in such high level 'problem solving skills' as 'organisation', 'analysis', 'definition', 'development', 'refinement', 'evaluation' etc, is somehow dangerously reductionist. We feel, (quite rightly, I think) that such reductionism robs design activity of its essential character.

Now I think there is a way out of the apparent impasse here; but we need to step back from the 'problem solving' model of designing and look in a different direction. The search here is for a way of describing, and reflecting on, design, through a set of 'criteria' that can provide us with a methodological framework which will illuminate both design activity and the products of design. In a discussion more fully developed elsewhere ${ }^{7}$ I have argued that design activity can be characterised as a species of 'language' consisting of a 'vocabulary', having a grammar (syntax and semantics) which although in a sense 'rule-governed' (including in some of its aspects the kind of algorithmic 'rules' I've alluded to above), nevertheless undergoes constant metamorphosis and change, and that, if we look carefully at the products of designers, we can see this kind of metamorphosis in action. What I want to bring out here is the fundamentally metamorphic character of design; and it is this metamorphism that aptly enough characterises its 'creative' aspect. I want to argue that the 'creative' (and not merely the 'problem solving') aspect of design 
is amenable to analysis.

Indeed, design tends to be to thought of as a quintessentially creative activity; and it is at this point that we want to consider how the language-games we play qua design, can, as it were, acquire the kind of 'new joint' making it possible to grasp a new vision, cast old problems in a new light, glimpse new solutions, or even see new problems. We need to capture the sense in which the application of a rule (or rules) can nevertheless lead to new insights, new solutions to design issues; in short, to growth in particular design language-games. This, we feel, does not readily fit into the reductionist methodology of the problemsolving strategies we have been considering. As an example of this more 'creative' aspect of design activity at work, let us consider some of Le Corbusier's work. Writing in 1927, he argued that:

The architects of today, lost in the sterile backwaters of their plans, their foliage, their pilasters and their lead roofs, have never acquired the conception of primary masses. They were never taught that at the Schools. Not in pursuit of an architectural idea, but simply guided by the results of calculation [derived from principles which govern our universe] and the conception of a LIVING ORGANISM, the ENGINEERS of today make use of the primary elements, and, by co-ordinating them in accordance with the rules, provoke in us architectural emotions and thus make the work of man ring in unison with universal order. Thus we have the American grain elevators and factories, the magnificent FIRST FRUITS of the new age. THE AMERICAN ENGINEERS OVERWHELM WITH THEIR CALCULATIONS OUR EXPIRING ARCHITECTURE. [emphases in Le Corbusier's text] ${ }^{8}$

In terms of our discussion, notice first that Le Corbusier can be understood as claiming that the language-games (e.g. of classicism) being played by architects are headed for a dead end (if not already in one); they lack, for example, certain concepts, eg: a 'conception of primary masses'. Secondly, engineers are, on the other hand, able to work with such a conception, although not in any conscious conformity to any 'architectural idea; so here, he implies that the growth of a design vocabulary does in some sense require the acquisition of new concepts. Thirdly, in suggesting that the work of the engineers provokes 'architectural emotions', he shows an intuitive grasp of the ways in which such rules themselves are, at a deeper level, amenable to other forms of interpretation. Finally, he is not advocating the application of new rules; rather, he seems to be aiming at the different application of existing ones. This does not require that we attribute clairvoyant powers to Le Corbusier, or suppose that he had- at this point in timegrasped a whole new vocabulary of design in a 'flash'. What he did see, was that the cluster of language-games apposite to the engineering disciplines had possible application in an aesthetic domain. Thus, the rules of calculation and measurement in engineering science, which, as it were, impose particular structures on form, themselves undergo a subtle transformation in Le Corbusier's vision. Here, we might say, is direct evidence of the evolution of a fertile new viewpoint in architectural design; one where some of the rules of engineering design become fused into a creative adaption leading to the generation of a new aesthetic - an aesthetic of the machine - yielding a vocabulary of forms which was to dominate much of 20 th century architecture and design

To take another example, this time from a design historian; Reyner Banham, commenting on automobile design in the late 1940s and early 1950s, Banham draws attention to the changes in a society where obsolescence was rapidly becoming a major factor in product design and development. In such a society, he argues, aesthetic ideas were becoming as expendable as the artefacts that reflected them. Automobiles of the period exhibited this vividly; Banham suggests that automobile design stylists developed an iconography itself derived from jet aircraft of the period, an iconography which came to symbolise speed and power (through) association with aircraft technology) in the imagination of the public, who could recognise and respond to this mode of symbolisation, thus reinforcing it and entrenching it more deeply in the popular consciousness. By the '50s and early '60s we can see extensions of this kind of design 
methodology; there are by then a multiplicity of iconographies embedded in the popular imagination with respect to automobiles, ranging over not only iconographies of power and speed, but wealth, sex, individualism, freedom etc focused explicitly for example, through sports cars such as the Jaguar 'E' type.'

Banham is not merely offering a description here, but, rather, a commentary in the form of an analysis. The value of such a commentary is that it focuses our attention in a perspicuous way; it offers an explicit viewing point. We have an idea of 'power' (derived from the aircraft); from this is developed a mode of symbolisation; and we have a public which 'reads' this iconography which becomes reinforced and embedded in the popular imagination. As technology moves on, so the product disappears, taking with it the (equally transient) particular iconographic reading wherein lay its aesthetic appeal; the aesthetic thus disappears into oblivion along with the product.

By attending to actual examples of designers' work and by studying the kind of commentary offered by Banham, we can both illuminate, and explicate, the' processes' of design thus over- viewed. This kind of over-view offers organisational constructs which enrich the problem solving strategy by bringing out the metamorphic, and evolutionary character of designing. In attending to such commentaries, students can learn, both to clarify their own viewpoints, and also develop more sensitive and informed responses to design work. It can provide us with a conceptual 'resource' richer than that of mere 'problem-solving, and it offers a much more vivid characterisation of design activity.

\section{References}

1 For a recent commentary see D. Lamb(1991): Discovery, creativity and problem-solving. Aldershot, Avebury.

2 J. Dewey(1946) The challenge of democracy to education; in The problems of men. New York. Philosophical Library.

3 J. Locke (1690) An essay concerning buman understanding.

4 For a recent critique of the situated cognitivist approach to 'problem-solving' see Henessy, McCormick \& Murphy: The myth of general problem-solving capability: design and technology as an example. The Curriculum Journal Vol. 4 No.1 1994 p.7387.

5 See R. Penrose (1992): The emperor's new mind. Penguin, London

6 See R. Coyne \& A. Snodgrass: Is designing mysterious? challenging the dual knowledge thesis. Design Studies Vol.12 No.3 Jully 1991 p. 124-131

7 See T. Liddament: The metamorphosis of the design vocabulary. Design Studies Vol. 17 No.3 July 19961996 p.-303- 318

8 Le Corbusier(1970) Towards a new architecture. Architectural Press, London. p. 33

9 For a recent discussion linking contemporary iconographies with undrpinning ideologies, see D. Harvey(1990): The condition of postmodernity. Blackwell, Oxford 